\title{
Knowledge Management in the Fourth Industrial Revolution: Mapping the Literature and Scoping Future Avenues
}

\author{
Mohammad Fakhar Manesh, University of Rome Tor Vergata \\ Massimiliano Matteo Pellegrini, University of Rome Tor Vergata \\ Giacomo Marzi, Lincoln International Business School \\ Marina Dabic, University of Zagreb \& Nottingham Trent University \\ Published in IEEE Transactions on Engineering Management
}

FULL TEXT (DOI): https://doi.org/10.1109/TEM.2019.2963489

\begin{abstract}
Due to increased competitive pressure, modern organizations tend to rely on knowledge and its exploitation to sustain a long-term advantage. This calls for a precise understanding of knowledge management (KM) processes and, specifically, how knowledge is created, shared/transferred, acquired, stored/retrieved, and applied throughout an organizational system. However, since the beginning of the new millennium, such KM processes have been deeply affected and molded by the advent of the fourth industrial revolution, also called Industry 4.0, which involves the interconnectedness of machines and their ability to learn and share data autonomously. For this reason, the present study investigates the intellectual structure and trends of KM in Industry 4.0. Bibliometric analysis and a systematic literature review are conducted on a total of 90 relevant articles. The results reveal 6 clusters of keywords, subsequently explored via a systematic literature review to identify potential stream of this emergent field and future research avenues capable of producing meaningful advances in managerial knowledge of Industry 4.0 and its consequences.
\end{abstract}

Index Terms - Industry 4.0, Knowledge Management, Fourth Industrial Revolution, IoT, Internet of Things, Big Data, Smart Factory, Knowledge Sharing, Manufacturing Innovations, Cyber Physical System, Condition Monitoring, Cyber-Physical Production Systems, Digital Economy, Digital Transformation, Literature Review, Bibliometrics, Future Research, Forecasting, Technology Foresight

\section{MANAGERIAL RELEVANCE STATEMENT}

This study suggests the evolving field of knowledge management significantly influences organizational performance in the era of Industry 4.0. Findings reported in the literature clearly demonstrate that companies must consider the topic of knowledge management concomitantly with the implementation of Industry 4.0 innovations. Novel interactions between machinery and humans are imminent and will reconfigure organizational approaches to production, product development, and monitoring. Managers need to create an environment where the effectiveness of these upcoming transformations is clearly understood. In Industry 4.0, where change occurs rapidly, managers should consider their organization's capability of handling and managing high flows of knowledge resulting from the implementation of Industry 4.0. 


\section{INTRODUCTION}

Since its initial conceptualization in the nineties, knowledge management (KM) has become a wellestablished discipline in academia and business due to their increasing emphasis on results [1]. Knowledge is a key resource for gaining sustainable competitive advantage, concretely translated into more efficient business processes and quality improvement, as well as increasing firms' ability to recognize novel solutions and develop products that meet their customers' needs [2]. Although a widely agreed-upon definition of KM has not been established [3], Hedlund [4, p.76] defines it comprehensively as "the generation, representation, storage, transfer, transformation, application, embedding, and projecting of group and organizational knowledge." Thus, KM relates to a combination of processes that coordinate and capitalize on a firm's cumulative knowledge to achieve sustainability and adapt to emerging changes in the environment [5].

Recent technological advancements in the digital era have the potential to boost the knowledgedriven economy [6]. The fourth industrial revolution, also referred to as Industry 4.0 in the literature, has become a topic of interest in many research areas, such as engineering, computer science, electrical engineering, and material science. The paradigm refers to technological evolution and futuristic paradigms using smart and intelligent systems, automation, and digitalized production [7]. Industry 4.0 is a tool used to shift from a manufacturing paradigm where machines simply operationalize routines to digital manufacturing, where machines are capable of communicating with each other and collaborating autonomously [8].

However, the outcomes of these changes and their relationship to KM have been irregular, and the parameters involved are generally ambiguous [9]. For example, in a constantly-connected environment, machines monitor processes continuously and produce reports, increasing the potential for knowledge creation exponentially [9]. As a result of this activity, substantially more unstructured data and information are produced increases, which may congest the information system [10]. For this reason, to truly benefit from this digital transformation, organizations should improve their KM approaches so they can scan and detect meaningful pieces of information and develop more sophisticated uses of this knowledge. However, the ways in which firms are profiting from KM practices in the digital revolution era remain inconsistent and confusing [11]. Although some attention has been paid to specific concepts/technologies introduced by Industry 4.0, such as the Internet of things (IoT) [12] and big data [13], as well as their impact on KM, the Industry 4.0 phenomenon is fairly new, and no comprehensive studies have addressed the full extent of the problem thus far. Aiming to address this gap, an investigation of the main existing contributions regarding the relationship between KM and Industry 4.0 relationship is conducted. The methods employed, bibliometric analysis and systematic literature review of a dataset of 90 relevant papers, identify possible connections and research directions, through a systematization of the main existing contributions on the KM-Industry 4.0 relation. Bibliometric methodologies have contributed to the development of a wide range of fields, including management [14], knowledge management [15], and even Industry 4.0 [7] by helping scholars frame their streams of research in the 'tangled forest' of scientific proliferation.

Two overarching research questions guide this study. The first question, "How does the KM literature address the dramatic changes occurring in reason of the Industry 4.0 era?", allows us to synthesize and systematize current knowledge on the topic. The second question, "How will this development impact KM practices in the future?", helps set a tentative agenda for future research in the KM field. Thus, this paper makes a multifold contribution. For theory building purposes, it explores the knowledge structure, thus systematizing the emergent streams of the field, and gaps, indicating future directions of KM research as it relates to Industry 4.0. The study also offers a set of insights regarding emerging technologies and their practical application in organizations to improve KM systems/practices. The study is organized as follows. The next section describes the methodological approach, while the third section presents the bibliometric and cluster analysis results, and the fourth section synthesizes and discusses future research avenues. Finally, the fifth section discusses the conclusions and limitations of the study. 


\section{METHOD}

Since Industry 4.0 is a recent development, to review the current literature, the Scopus database was selected as it offers the widest coverage of documents throughout the available databases [16]. However, to assure the maximum level of reliability, the results were also cross-validated with the Web of Science Core Collection and EBSCO to confirm the inclusion of all the relevant studies. No discrepancies were detected, confirming Scopus as the most comprehensive dataset.

After several iterations and based on the current study's research questions, the following search string was identified as the broadest yet most effective to retrieve relevant papers. The query was performed on February 18, 2018, using the following string: TITLE-ABS-KEY ("knowledge management") AND (TITLE-ABS-KEY (industry 4.0) OR TITLE-ABS-KEY (revolution 4.0) OR TITLE-ABS-KEY (fourth AND revolution) OR TITLE-ABS-KEY (4th AND revolution) OR TITLE$A B S-K E Y$ (4th AND industrial)). The TITLE-ABS-KEY operator conducted a Boolean search by running the aforementioned query of the selected terms in titles, abstracts, and keywords, which identified 107 articles. The results consider all journal articles and conference papers without a timeperiod limitation due to the novelty of the topic. The first paper was published in 2014, and thus, the entire dataset covers a five-year time period (i.e., 2014-2019). However, only the most relevant subject areas were chosen: arts and humanities, business, management and accounting, chemical engineering, chemistry, computer science, decision sciences, economics, econometrics and finance, energy, engineering, environmental science, material science, psychology, and social sciences.

The initial dataset was refined further by dropping 14 records because they were conference book proceedings that only contained a table of content, i.e., the list of papers of the conference. Next, a manual screening of the dataset was performed to ensure the papers contain a concrete focus on KM and Industry 4.0, meaning that each paper, beyond presenting a study of an Industry 4.0 technology or paradigm, offers concrete implications for organizational KM systems or one of the elements involved (e.g., KM platforms, KM interfaces, or human use of KM systems). Two authors reviewed the set independently, and their opinions differed on 3 papers, which were excluded. After this refinement, a total of 90 papers remained in the final dataset.

To analyze the intellectual structure of the research reported on in this dataset, bibliometric analysis was performed and the specific technique was based on the visualization of similarities (VOS) [17], using the author's keywords as the unit of analysis. Then, a systematic literature review developed the topics identified in the keyword analysis using Tranfield, et al. [18] approach.

Prior to performing the bibliometric analysis, the dataset was pre-processed in a Microsoft Excel spreadsheet by associating qualitative attributes (e.g., the methodology employed and the main KM concepts touched upon) and bibliometric parameters related to the volume and influence of the research with each paper. During this stage, it was also crucial to check the input variable of the analysis (i.e., the authors' keywords) for possible missing data, other errors (e.g., mistyping/misreading) and consolidate the dataset. Some keywords are the same term but written differently, thus creating duplications and affecting the analysis [19]. For example, the keywords 'IoT' and 'Internet of things' are different terms but refer to the same meaning; therefore, they needed to be reconciled into a single keyword. Subsequently, to conduct the main analysis, we used VOSviewer version 1.6.6 software to perform the co-word analysis, based on the authors' keyword aggregation mechanism [20]. To ensure the maximum level of inclusion and follow best methodological practices, this study considered the number of co-occurrences of a keyword at the lowest level, and thus, the keywords must co-occur at least once in the dataset [21]. The technique utilizes keywords to form a knowledge structure that enables the identification of the main topics in a research field and their internal relationships [22]. This approach relies on the fact that the more a keyword occurs in combination with others across the dataset of documents, the stronger the connection between them. In VOSviewer, the aggregation technique results in a two-dimensional map that uses a co-occurrence matrix of keywords generated from the presence of co-occurrences and their frequency, which relates to their spatial proximity [20]. Technically, this method formulates 
measures of the similarities between lexical associations; hence, it assesses in-depth semantic interconnectedness and performs a set of routines to build a spatial map in which the items (i.e., authors' keywords) are spatially distributed according to the distance between any pair of items. Therefore, considering these distances, a cluster analysis was also performed [20] because two spatially close keywords (i.e., keywords with a higher co-occurrence frequency) have a higher likelihood of being grouped by the algorithm in the same cluster. In a VOSviewer visualization [23], each point identifies a keyword that co-occurred at least once, with the size of the bubble indicating the number of occurrences and the assigned color identifying the cluster. The distance between terms corresponds to the frequency of their co-occurrence.

Finally, a systematic literature review was conducted [18] based on the VOS cluster analysis results. To discover the core descriptors or research area of each cluster, we selected keywords with the highest number of occurrences. This enabled the analysis of the most important papers containing the most impactful keywords in each cluster. Following the methodological prescriptions in [18, 21], the dataset was reviewed by all four authors, and interpretations were discussed through several visà-vis interactions to double-check the selected keywords and papers assigned to a specific stream in each cluster. All four authors discussed the most relevant papers in the dataset according to the relevance of the topic, the magnitude of the findings and their implications, the relevance of the outlet of the publication, and the normalized citations of the paper.

\section{RESULTS}

The main results of the bibliometric analysis can be summarized in Figure 1, which illustrates the results of the VOS analysis. For a more coherent visual presentation, only the most influential keywords are displayed in the figure, and the full set of keywords and their relative frequencies are presented in Table 1. The VOS analysis shows six different clusters related to different research areas emerging from studies of KM and Industry 4.0. Next, we present the results of the systematic literature review performed based on the VOS analysis.

\section{A. Green Cluster}

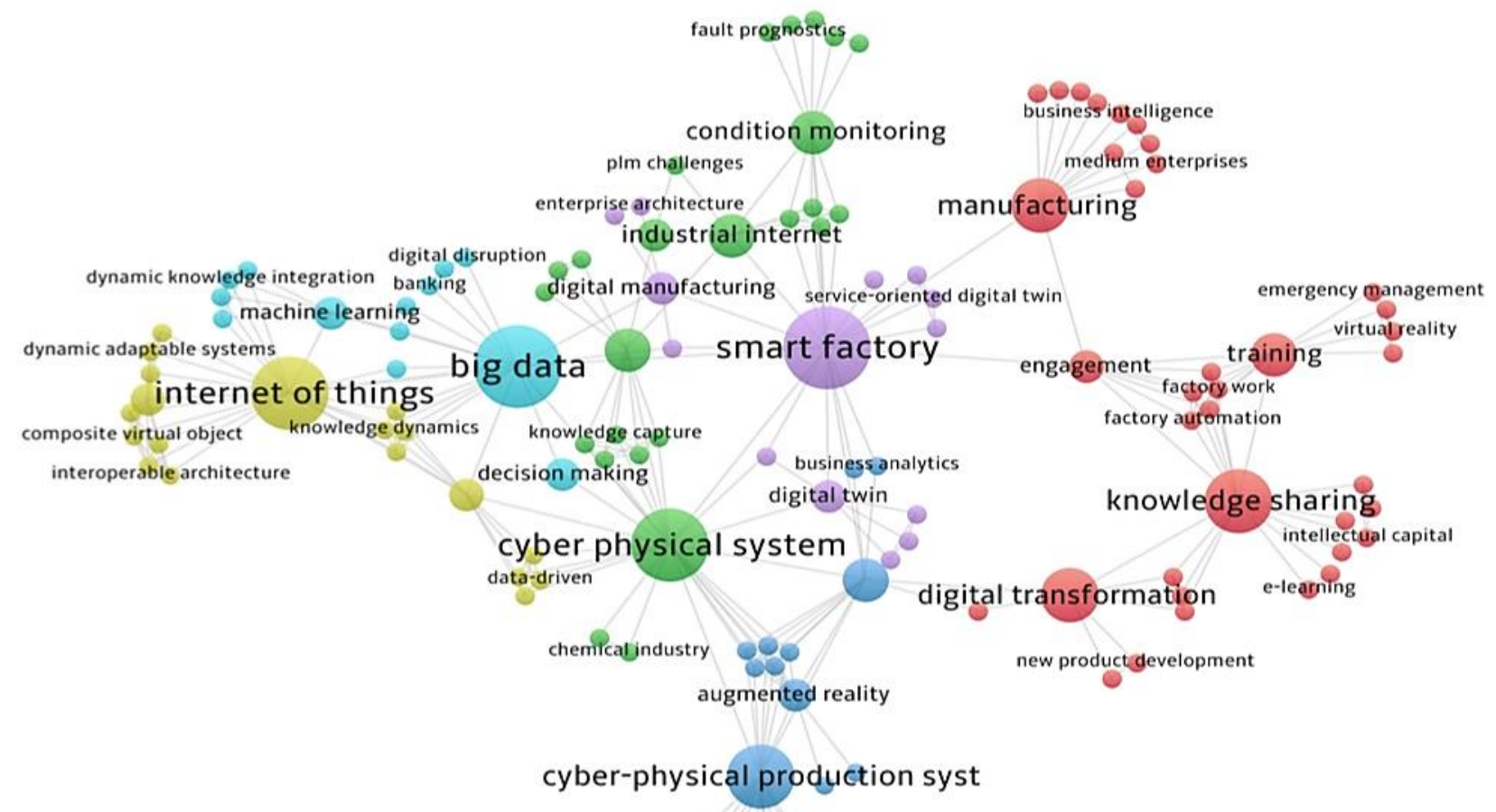

Fig. 1. Diagram of the VOS keyword analysis results. 
Keywords in the green cluster revolve around two sub-streams, namely cyber-physical systems (CPS) and condition monitoring (e.g., intelligent systems, product lifecycle management, process industry, preventive maintenance, fault prognostics, platforms). The first sub-stream addresses CPS as the central object of investigation in the era of Industry 4.0, which has already received extensive attention in both the academic and industrial domains [24]. Specifically, CPS research encompasses many subjects, including industrial design, industrial technologies, computer science, and electrical engineering. Practical examples of this technology are self-driving cars, robot surgeons, smart manufacturing, smart electric grids, implanted medical devices, and intelligent buildings [25]. However, from a technical viewpoint, CPS is defined as the integration of physical processes with their computations in a way that both the virtual and physical parts of the system interact effectively [26]. Thus, CPS, as a class or collection of systems, enables this integration, which facilitates computation, communication, controlling operation, and interactions with the task environment, either physically or virtually [27]. KM envisions CPS as a facilitator of knowledge services in smart systems [28]. CPS contains collections of miscellaneous data stored within different links/nodes, for example, databases filled with software vendors and NoSQL. This integrated deployment of knowledge increases the possibility of retrieving and exploiting knowledge more efficiently [28].

In one of the studies dealing with KM and CPS, Sivanathan, et al. [29] propose a specific approach to knowledge capture methods, promoting the real-time mapping of information and facilitating its retrieval and reusability. During the product lifecycle process, companies using traditional knowledge capture approaches have difficulty storing such knowledge, which often results in losing it. The authors suggest instant user logging in a virtual design environment called the virtual-aided design engineering review (VADER) system. This knowledge capture method allows for automatically integrating structured and unstructured data via a ubiquitous integration and temporal synchronization routine (UbilTS).

CPS also relates to both vertical (i.e., within a company and its hierarchy) and horizontal (i.e., between companies or different organizational units and sites) knowledge sharing. Scheuermann, et al. [30] propose a CPS application for incident management and IT services. Their approach allows instant control of incidents by collecting data generated by wearable devices and sharing this information throughout the system, which cannot be done using traditional hand-written reports. In another study, Mládková [31] suggests implementing a CPS in the aviation industry to help pilots fly planes with more security and precision. A CPS, which captures and shares information about problematic situations, can reduce faults occurring due to inefficient interactions between humans (i.e., tacit and explicit knowledge) and technical machines (i.e., explicit knowledge).

The second sub-stream of this cluster on condition monitoring is focused on individuating faults in machines, processes, or systems. In the Industry 4.0 era, the high demand for productivity and responsiveness in manufacturing processes necessitate automation in various environments. For this reason, machines should be monitored closely to proactively resolve problems that may halt or slow down a production system. A protocol is used to define and set the machine's normal functioning state, thus allowing the program to detect any deviation [32]. Condition monitoring has made considerable contributions in a variety of fields, including electronic engines [33], wind turbines [34], and the railway industry [35]. From a KM perspective, a high volume of data tends to be generated, so the objective of condition monitoring is to use an intelligent CPS to handle various complicated situations and deal with failure prediction and planning repair work automatically [32]. Knowledge content/standards for the monitoring should be available to an intelligent CPS, as it enables the automatic operation and maintenance of the system.

Traditional monitoring techniques rely on programmed maintenance or, in some cases, human prerogative, to make decisions about fault prediction and maintenance planning. However, due to the growing complexity of production systems, these solutions may result in either an excessive or insufficient level of intervention or the inability to respond to problems in time to prevent a system or machine shutdown. However, a smart system can monitor the real-time status of equipment and regulate maintenance accordingly [36]. $\mathrm{Wu}$, et al. [36] propose an interactive visual-analytics 
approach to manage online equipment dedicated to condition monitoring. The authors present a semisupervised system using advanced analytical algorithms (i.e., a Gaussian mixture model with a Bayesian framework) and natural visualization design to extract valuable information from data collected via sensors and devices. This approach enables operators and managers to enhance their knowledge, make better use of inputs, guide the autonomous analytics, and obtain more reliable results.

Similarly, Cao [37] presents an ontology-oriented framework using an intelligent system to support decisions regarding condition monitoring tasks (e.g., fault alarm recognition and maintenance plans). The intelligent system functions according to two dimensions; a core reference ontology for capturing general conceptions and associations, and a second combines a collection of domain ontologies to integrate condition monitoring and manufacturing knowledge.

\section{B. Aqua Cluster}

Keywords belonging to the aqua cluster focus on a variety of terms related to big data (e.g., banking, decision making, machine learning, financial sector data, and product data). Big data is generated continuously through digital processes and transferred via multiple devices and systems. In the literature, the concept of big data consolidates around three dimensions, the traditional ' $3 \mathrm{Vs}$ ': volume, velocity, and variety [38]. Volume refers to the mass of data produced, while velocity refers to the speed at which data are produced, obtained, or transferred, and variety represents the growth of new data types that are assimilated. However, these three dimensions place more emphasis on the purely technical side of big data, and thus, researchers have begun to enlarge the set of attributes. First, a challenge exists in relation to the data generated daily from these digital processes. A large quantity of big data may result in unstructured forms of data that are less reliable. Thus, the level of reliability of such complicated forms of data is referred to as 'veracity' [39]. Nevertheless, unstructured data has also proven to be a useful asset in the development of several fields, including risk management [40], customer relationship management [41], and the banking industry [42]. For example, unstructured data are easy to store, retrieve, and analyze. Thus, the same combination of unstructured data may be evaluated differently and have a different 'value,' according to organizational needs and uses.

Big data is a KM enabler as these digital processes provide a large base of information that can be turned into knowledge. Therefore, a task for KM is to better structure such inputs through, for example, codification, personalization, and representation, which improves data interpretation [43]. Transforming big data into understandable knowledge so that it can be used or shared is also a key factor in promoting innovation [44].

Several papers in this cluster deal with the possibility of increasing knowledge creation from big data. For example, Costa, et al. [44] propose a novel conceptual framework using knowledge representation for unstructured data sources. This technique facilitates the transformation of unstructured data into a representation schema that is more structured, usable, and sharable when needed. To do so, the authors use an enriched vector space model (i.e., semantic vector) developed to support ontologies. Using semantic technologies helps enrich the implicit information within documents' complicated relationships (i.e., semantic associations), thus extracting additional information from documents.

Bao, et al. [45] focus on using semantic web technologies and a semantic web rule language in the steel industry. Ontology modeling is used to turn a large volume of data, such as historical stored data, into valuable knowledge, thus providing knowledge exchange and reusability for future modeling and integration. The authors also discuss the characteristics of different methodologies used for ontology modeling and sematic deductions. Similarly, Peroni and Vitali [46] use semantic web technologies but apply them to an Italian fashion company, Imperial Fashion. The authors present an ontology model ( $O W L 2 D L)$ for converting all original data stored in the company's database into knowledge, unifying the data for product sales. Hence, it is possible to apply different visualization methods and various interfaces with greater interactivity, as well as employ self-operating analytical 
assets. Cárdenas, et al. [47] focused, instead, on the necessity of fully integrating big data logics into organizational and information systems, typically referred to as KM systems. The results of this integration can boost the intellectual capital of personnel, who can then benefit from improved machine-based data collection.

Another specific case of big data integration and utilization was conducted by Mungai and Bayat [42] in the banking sector. The authors use two cases, Capitec and FirstRand, and employ the clients' information, specifically interactions and relationships with clients and account holders. All of this information is used to design innovative and improved client-centered services. Changes in the branches' design, back-office policies (e.g., offering flexible working hours), and data-driven decision making were implemented, which increased client satisfaction.

\section{Purple Cluster}

The purple cluster reflects the discussion on smart factories with keywords such as digital manufacturing, sustainable manufacturing, and digital twin. The trend toward building smart factories has stimulated a new approach to analytic- and predictive-driven production thinking [48]. Indeed, the smart factory concept is not limited to traditional factory automation approaches, such as using robots to substitute human labor or improving the efficiency of production processes. Instead, this concept involves the use of analytics to explore the feasibility of possible solutions [48]. For this reason, from a KM perspective, the term smart factory does not relate simply to the use of technologies in an organizational setting; it represents the practical advantage that an organization can acquire by using knowledge in the development of its production processes [49]. Increased knowledge about the production process in a smart factory context can be obtained through digital twin technology, which is an extensive physical and operational description of assets and, thus, a 'virtual copy' of products, machines, and other systems involved in the production process [50]. This gives to human operators and access to a technical process that may not be completely known or knowable.

Padovano, et al. [51] propose an application-based model using digital twin technologies, which allow operators to foresee the future status and position of physical assets involved in the production system. Thus, operators' decision-making ability and knowledge acquisition and use are enhanced. Similarly, Longo, et al. [49] aimed to develop a more human-centered manufacturing paradigm where employees can acquire ubiquitous knowledge about processes, which can facilitate business and production performance. To do so, the authors propose a human-centric approach, the 'industrial internet pyramid'. It uses a service-oriented digital twin as a kind of 'on-demand' service. This digital twin is integrated with an audio system that captures inputs, such as spoken information. A close interaction between the CPPS and employees facilitates a knowledge process based on the intuitive knowledge obtainable by this eased interaction and, thus, enables further knowledge creation.

The smart factory concept is also related to modeling processes to enrich predictive lean production. On this topic, Lee, et al. [48] present a novel approach to integrate knowledge flows and business process management. In their study, the authors propose a process modeling approach that facilitates analytics by using the extensible markup language (XML) process modeling language. This analytic KM approach provides businesses insights using past experience to frame upcoming and existing problems.

Finally, human competencies are also important in a smart factory environment. GraczykKucharska, et al. [52] formulate a framework for managerial competencies necessary to fully benefit from this type of context. One of the elements confirmed is the ability and necessity of exchanging practical engineering knowledge and coordinating processes more effectively in relation to knowledge of employees' competencies. This, in turn, enables a faster response to market demands and much quicker resource access.

\section{Yellow Cluster}


The yellow cluster mainly contains keywords that refer to the role of the Internet of things (IoT) (e.g., internet of services, the web of objects, virtual objects, microservices, interoperability, semantic integration). The IoT is envisioned as the connectivity of every object through the internet to send, share, exchange, and comprehend data and information [53]. Thus, IoT services generate new data that can be turned into useful knowledge, which enables the implementation of certain types of smart solutions and applications (e.g., smart health care, smart homes, connected cars, self-driving vehicles, smart farming, and smart agriculture) [54].

At a more practical level, the IoT allows Industry 4.0 systems to integrate and connect effectively and reliably, from both a syntactical and semantical perspective. This places the IoT at the core of the whole industry architecture [55]. Each object has an individual virtual identity and the capacity to integrate and interact independently within a network of other similar or different machines [56]. However, single objects may have different semantic protocols that need to be interpreted to establish autonomous communication [57], which is the IoT's role, thus providing access to real-time information from sensors, devices, and even objects. From a knowledge management perspective, this cluster also contains various keywords, such as knowledge dynamics, knowledge management systems, and knowledge-driven architecture. When viewed through the KM lens, the IoT allows more ways to manage and monitor knowledge in an organization and requires innovative knowledge management systems that can adapt to more complex knowledge flows [12]. Moreover, the IoT can be considered a prominent enabler of all KM processes[12] since the objects' interconnectivity relates to an expanding potential for data generation, storage, acquisition, transfer, and application [58].

For this reason, $\mathrm{KM}$ is particularly interested in the management of platforms to fully exploit the benefits of IoT. Jarwar, et al. [53] propose an IoT service platform called 'web of objects.' This platform favors the application of interoperable microservices and the virtualization of objects. In doing so, the authors mention three major concerns: (a) how to connect of all these objects and control the complexity of the semantic cooperation between them, (b) how these objects aim to interpret information and data provided by IoT services, and (c) how to monitor the functionality of every object rapidly and realize a less centralized management of the system, which also provides high levels of scalability, recovery, and resiliency. Resolving these concerns would require further technological advancements and applications, as well as faster improvement and replacement in terms of the IoT. The architecture proposed uses platforms that simplify the activities of single objects located in a variety of different domains (e.g., data transfer and data capture). Rodríguez-Molano, et al. [56] also focus on the role of interconnected platforms in an IoT system and present several examples of IoT platforms. For each of them, the authors discuss characteristics, advantages, and different levels of diffusion among transitional, emerging countries.

Burzlaff and Bartelt [59] focus on the IoT's impact on production processes. Specifically, languages with normalized semantics may improve automation in the component integration process, thereby simplifying manual integration (e.g., a 'plug and play' approach). When complicated specifications are involved the production process in terms of design, manual integration is not recommended. Indeed, manual integration relies on informal standards and ad hoc solutions that are not re-usable, thus impairing knowledge integration. The proposed solution is an interface specification based on a knowledge-driven architecture for the re-use of these combinations and integrations. Similarly, Toc and Korodi [60] discuss the challenges of automating component integration, which can be summarized as the need for particular protocols and lower costs of hardware, software, and middleware tools to ease the knowledge exchange of integrators. The authors used a Modbus-OPC UA wrapper as hardware, IoT 2040 as a middleware tool, and a Node-RED software environment. In their experiment, developments were tested in a real case scenario of a wastewater pumping station.

Finally, the IoT concept is quite central to the whole intellectual structure of the field, and hence, it is also closely related to other central keywords, such as big data, predictive maintenance, machine learning, and sensors. This also means, for example, that the literature often addresses the joint effects of the IoT and big data on KM. Indeed, Candanedo, et al. [61] paper focuses on a case study of a 
heating, ventilation, and air conditioning systems (HVAC). Such systems monitor the temperature, humidity, and indoor climate to obtain the most favorable production environment. The authors dwelled on the important role of IoT sensors in supporting intelligent systems' ability to transfer information and on big data as a source of useful, more detailed information, which facilitates decision-making processes, including those involving predictive maintenance, failure anticipation, and emerging demand prediction.

\section{E. Red Cluster}

Keywords in the red cluster focus on a broad range of aspects associated with several organizational transformations brought forth by the industry 4.0 (e.g., factory of the future, factory automation, organization 4.0, operator 4.0, factory work, and new product development). One specific sub-stream could be aggregate around the evolutions occurring in manufacturing, with a strong focus on humans' role in relation to knowledge exchange in the digital era. The manufacturing developments are generally related to creating adaptive and connected value chains to handle the complexity of the market, thus creating extra value for customers during product life cycles [62].

Specifically, KM views manufacturing from the perspective of the 'factory of the future' (FoF) concept, which involves the integration of production technologies with IT to improve automation via cyber-physical systems [63]. Consequently, sufficient data and information can be provided about each production element, facilitating their connection accordingly [63]. The FoF is a virtual milieu of interaction based on knowledge transfer practices involving both the eternal environment, such as collaboration with external resources (e.g., other companies), exploiting new connections with local ecosystems (e.g., universities and policymakers), exchanging best implementation practices (e.g., sharing successful stories), using the internal environment as a space to learn and improve knowledge transfer approaches (e.g., 'train the trainers'), and facilitating a culture of sharing knowledge among workers [62].To explore this perspective, Zangiacomi, et al. [62] investigate best practices for an efficient FoF in an Italian manufacturing organization. The authors identify two key drivers of the implementation: technology investments in the FoF (e.g., adapting lean management approaches and training specialists on specific technological skills), the organization's ability to realize the FoF, and investigating the shift in the company's business model and its consequences. This contributed to the readiness of the organization and to the promotion of knowledge transfer.

Another important concept related to manufacturing approaches in the digital era is the idea of the human operator, known as 'operator 4.0,' specifically stressing the importance of knowledge sharing. In an organizational Industry 4.0 environment, human capital has a strong potential for organizational knowledge transfer by exchanging and integrating individual knowledge. Accordingly, Li, et al. [64] conduct a study of knowledge mapping by using individual perspectives to realize how sharing knowledge (i.e., tacit or explicit) influences the organization's information systems. Using the 'make time to discuss, explore differences, encourage respect, take responsibility' (MEET) model, which promotes mutual respect in the work environment, the authors study and link knowledge sharing activities, the intensive technological adoption of the Industry 4.0 paradigm, and organizational logics, coining the term 'organization 4.0' to describe this approach.

Aromaa, et al. [65] conducted another case study focused primarily on the human aspects of the Industry 4.0 manufacturing transformation, proposing the 'Facory2Fit' project for work engagement and involvement. The project is based on four components: knowledge-sharing ability and interactions using discussion platforms, information visualization using augmented reality technology, task and workplace design using 3D software, and training tools used on a training platform. All the components were found to have positive impacts on workers' performance and wellbeing.

A second sub-stream refers to the role of digital transformation (DT), which revolutionizes the way work is performed rather than focusing solely on the requirements of the physical environment (e.g., construction and manufacturing). This stream, in comparison to the other in this cluster, places more emphasis on the organizational component of transformation. Indeed, DT is defined as a digital 
approach to connect people, IT facilities, and machines. However, DT has been mainly approached from a technical perspective so far, stressing roles and the effects of technology platforms and their integration on organizational change, while consequences for people are addressed less frequently [6]. In a transforming organization, people should be considered an asset that can deal with complex knowledge domains through rapid collaboration and exchanges. From a KM perspective, focusing on the role of people during digital transformation leads to a stronger ability to develop innovations [66], and therefore, they are an important source of competitive advantage [67].

In the dataset, several successful concrete cases of DT implementation are described. Wolf, et al. [68] discuss the successful use of DT in a project called 'Healthy Work Pioneer Industries.' They state that successful drivers include shifting the mindset of the management, foreseeing the potential for innovation in different sectors, and motivating knowledge transfer within the organization. Another successful DT case is in the banking sector in Africa, described by Ochara, et al. [69]. The aim is to facilitate cashless banking for the $A B C$ Bank group. In their approach, the authors address the increasing need to capture knowledge of experiences regarding DT in Africa. Finally, BibaudAlves, et al. [70] studied DT in a new product development (NDP) process introduced in a French furniture manufacturing company. The DT was motivated by a company crisis caused by both managerial and technical backwardness. The first intervention was made in relation to the technology needed to improve the company's data collection and processing, which led to the creation of a KM (i.e., formalization and computerization) system. Although this first intervention was successful, other organizational areas still need improvement and revision, such as developing new competencies and skills, process management approaches, and decision-making procedures. Thus, the NDP redesign needs to be human-centered to handle resistances to change and unleash the true potential of human capital. Finally, Ilvonen, et al. [71] focus on problems related to knowledge protection during a digital transformation. These challenges may manifest in the tools used to protect proper knowledge manifestation, legal regulations, and approaches to balancing the necessity of transferring and securing knowledge.

\section{F. Blue Cluster}

The blue cluster also concerns the human-machine relationship, but in this case, the focus is oriented more specifically toward production processes (e.g., augmented reality, problem-solving, cyber-physical human system, cyber-physical market visualization, process simulation visualization, production modeling, and simulation process building). The first sub-stream addresses cyber-physical production systems (CPPS) as a new production system that emerged from the industrial application of cyber-physical systems [72]. CPPS is described as a set of production systems acting on feedback systems, resulting in an adaptive and predictive approach [26]. An example of CPPS is an on-demand print service offering high-speed printing, which requires avoiding equipment failures (e.g., paper jams) by controlling and initiating rapid shutdowns if necessary [26]. From a KM perspective, CPPS implementation calls for not only changes in the technical side, such as processes and systems, but also human-based skills and organizational competencies [73]. Thus, CPPS implementation promotes cultural change by empowering workers to become decision makers rather than simply data handlers [74]. Ansari and Seidenberg [74] discuss interactions between the human component and CPPS during problem-solving processes. The authors propose to discover the facilitating factors involved in knowledge transfer, reciprocal learning, and synergy in the smart organization context. A management portfolio matrix is used to identify environments in which human-CPPS interaction may occur. Their study confirms that CPPS learn not only from human decisions (e.g., using machine learning techniques) but also from communicating with humans. Similarly, Ansari, et al. [27] introduce 'problem solution and problem-solver' ontology, a semantic framework capable of identifying optimal conditions (i.e., states) to regulate human-CPPS interaction in a problem-solving context. Specifically, this ontology is able to frame a task or problem and identifies the best configuration for human-CPPS interaction. 
The second sub-stream deals with the role of process modeling and focuses on the design of production processes. Indeed, incorporating powerful Industry 4.0 technologies into traditional production systems demands a more thorough consideration of the necessity of adaptations and shifts in capabilities for true integration. For example, in a traditional production system, IoT technologies may ease customization, providing more flexibility as real-time changes in demand or requests can be adjusted easily during the production process based on further feedback loops between cyberphysical systems [75]. However, this also means dealing with a great variety of system conditions and statuses/states and, thus, dealing with greater complexity considering that all the processes need to be coordinated and controlled efficiently and effectively. For this reason, Grum and Gronau [76] propose a modeling process language using augmented reality integration to understand coordination requirements in what they call 'non-transparent processes.' Their approach enables visualizing and envisioning prospective tacit knowledge exchanges, complex coordination mechanisms, and a full simulation of the processes involved.

\section{DISCUSSION AND DIRECTIONS FOR FUTURE RESEARCH}

We created Table 1 to summarize the results of our study. The table synthesizes the intellectual structure of the emergent field of KM after the advent of Industry 4.0. Our primary goal is the systematization of this research field, as stated in our first research question. Since Industry 4.0 is such a recent phenomenon, systematizing its impact on KM is a strong contribution. For this purpose, each cluster indicates the main research areas, described in detail in the previous section, as well as the full set of keywords, and some exemplary references from the literature. However, addressing our second research question requires offering a tentative agenda for future research in this area based on the identified gaps. Thus, we highlight more recent sub-streams of research and the main KM processes touched upon in the literature to identify some useful areas of further development in future studies. 


\begin{tabular}{|c|c|c|c|c|c|}
\hline Cluster & Sub-Topic & Keywords (co-occurrence numbers) & $\begin{array}{l}\text { Exemplary } \\
\text { References }\end{array}$ & $\begin{array}{l}\text { Most acquired KM } \\
\text { process }\end{array}$ & Future Research Questions \\
\hline \multirow[t]{2}{*}{ 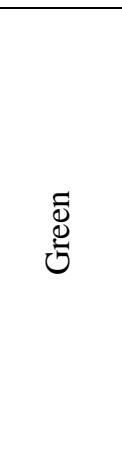 } & $\begin{array}{l}\text { Cyber-Physical } \\
\text { System }\end{array}$ & \multirow{2}{*}{$\begin{array}{l}\text { cyber physical system (6); condition monitoring (3); product } \\
\text { lifecycle management (3); industrial internet (3); platforms (2); } \\
\text { chemical industry (1); decisional dna (1); design review (1); } \\
\text { multimodal time synchronisation (1); plm challenges (1); product } \\
\text { development (1); semantic technology (1); set of experience } \\
\text { knowledge structure (1); supply chain network (1); time series } \\
\text { data (1); user logging (1); visual analytics (1); intelligent systems } \\
(1) \text {; manufacturing process (1); process industry (1); } \\
\text { manufacturing data (1); preventive maintenance (1); fault } \\
\text { prognostics (1); knowledge capture (1); knowledge engineering } \\
\text { (1). }\end{array}$} & {$[29],[30],[31]$} & $\begin{array}{c}\text { Knowledge } \\
\text { Documentation } \\
\text { Knowledge Transfer }\end{array}$ & $\begin{array}{l}\text { - How can CPS evolution } \\
\text { transform learning in an } \\
\text { organization? } \\
\text { - What is the effect of this } \\
\text { evolution on different level of } \\
\text { learning (i.e. individual, group } \\
\text { and institutional level)? }\end{array}$ \\
\hline & $\begin{array}{l}\text { Condition } \\
\text { Monitoring }\end{array}$ & & {$[36],[37]$} & Knowledge Creation & $\begin{array}{l}\text { - How can condition monitoring } \\
\text { systems/techniques develop } \\
\text { better management of } \\
\text { uncertainty for PHM systems? }\end{array}$ \\
\hline$\frac{\pi}{\tilde{Z}}$ & Big data & $\begin{array}{l}\text { big data (7); decision making (2); machine learning (2); digital } \\
\text { disruption (1); product data (1); financial sector (1); banking (1); } \\
\text { knowledge management processes (1); dynamic knowledge } \\
\text { integration (1); platforms iot (1); predictive maintenance (1); } \\
\text { semantic interoperability (1); sensors (1) }\end{array}$ & $\begin{array}{c}{[44],[45],[46],} \\
{[47],[42]}\end{array}$ & $\begin{array}{l}\text { Knowledge Application } \\
\text { Knowledge Acquisition } \\
\text { Knowledge Creation }\end{array}$ & $\begin{array}{l}\text { - How can Big data capabilities } \\
\text { transform new knowledge into } \\
\text { new competitive advantage? }\end{array}$ \\
\hline$\stackrel{\dddot{a}}{\rightleftarrows}$ & Smart Factory & $\begin{array}{l}\text { smart factory (7); digital manufacturing (2); digital twin (2); } \\
\text { enterprise architecture (1); grinding process (1); human-centric } \\
\text { industrial internet (1); industrial internet of services (1); rami4.0 } \\
\text { (1); service-oriented digital twin (1); sustainable manufacturing } \\
\text { (1); competency management (1); knowledge creation (1); } \\
\text { ubiquitous knowledge (1); web-based knowledge sharing } \\
\text { platform (1) }\end{array}$ & $\begin{array}{c}51],[49],[48], \\
{[52]}\end{array}$ & $\begin{array}{l}\text { Knowledge Transfer } \\
\text { Knowledge Acquisition } \\
\text { Knowledge Creation }\end{array}$ & $\begin{array}{l}\text { - How business models are } \\
\text { transformed in regard with } \\
\text { smart factory context? }\end{array}$ \\
\hline$\frac{3}{0}$ & $\begin{array}{l}\text { Internet of } \\
\text { things }\end{array}$ & $\begin{array}{l}\text { internet of things (6); interoperability (2); internet of services (1); } \\
\text { interoperable architecture (1); composite virtual object (1); data- } \\
\text { driven (1); dynamic adaptable systems (1); fault diagnosis (1); } \\
\text { microservices (1); knowledge management systems (1); } \\
\text { knowledge dynamics (1); knowledge-driven architecture } \\
\text { composition (1); plug-and-play control (1); semantic integration } \\
\text { (1); smart power grids (2); system monitoring (1); tacit } \\
\text { knowledge (1); virtual object (1); web of objects (1) }\end{array}$ & $\begin{array}{c}\text { [53],[56],[59],[ } \\
60],[61]\end{array}$ & Knowledge Transfer & $\begin{array}{l}\text { - How can IoT/ICT technologies } \\
\text { transform new innovation } \\
\text { paradigms (e.g., inbound open } \\
\text { innovation)? }\end{array}$ \\
\hline$\stackrel{d}{\mathscr{Q}}$ & Manufacturing & $\begin{array}{l}\text { knowledge sharing (5); manufacturing (4); digital transformation } \\
\text { (4); training (3); engagement (2); business intelligence (1); } \\
\text { business process management (1); communication (1); } \\
\text { computer-integrated manufacturing (1); e-learning (1); } \\
\text { emergency management (1); emergency preparedness (1); }\end{array}$ & {$[62],[64],[65]$} & Knowledge Transfer & $\begin{array}{l}\text { - What is the relationship } \\
\text { between risk of knowledge } \\
\text { leakage and firm's openness? } \\
\text { - How can firm's openness lead } \\
\text { to knowledge leakage? }\end{array}$ \\
\hline
\end{tabular}




\begin{tabular}{|c|c|c|c|c|c|}
\hline & & $\begin{array}{l}\text { factory work (1); intellectual capital (1); literature review (1); } \\
\text { medium enterprises (1); new product development (1); } \\
\text { organizational learning ambidexterity (1); participatory design }\end{array}$ & & & $\begin{array}{l}\text { - How can risk of knowledge } \\
\text { leakage transform firm's } \\
\text { perspective for openness? }\end{array}$ \\
\hline & $\begin{array}{c}\text { Digital } \\
\text { Transformation }\end{array}$ & $\begin{array}{l}\text { (1); product-service (1); product-service system (1); sentiment } \\
\text { analysis (1); simulation (1); sustainable development (1); user } \\
\text { studies (1); value chain (1); value creation (1); virtual reality (1); } \\
\text { worker model (1); workplace monitoring (1); factory of the future } \\
\text { (1); factory automation (1); operator 4.0 (1); organization } 4.0(1) \text {; } \\
\text { knowledge synergy (1); knowledge protection (1); knowledge } \\
\text { management evaluation (1). }\end{array}$ & {$[68],[70],[71]$} & $\begin{array}{l}\text { Knowledge Transfer } \\
\text { Knowledge } \\
\text { Documentation }\end{array}$ & $\begin{array}{l}- \text { How can DT lead to } \\
\text { successfulness of company’s } \\
\text { strategy? }\end{array}$ \\
\hline \multirow{2}{*}{$\stackrel{\mathscr{2}}{\mathscr{n}}$} & CPPS & \multirow{2}{*}{$\begin{array}{l}\text { cyber-physical production systems (5); process modeling (3); } \\
\text { augmented reality (2); problem solving (2); annotation system } \\
\text { (1); business analytics (1); collective intelligence (1); collective } \\
\text { intelligence system (1); community of practice (1); cyber- } \\
\text { physical human system (1); cyber-physical market visualization } \\
\text { (1); portfolio matrix (1); product innovation (1); set of experience } \\
\text { (1); smart innovation engineering (1); software architecture (1); } \\
\text { production modeling (1); simulation process building (1); system } \\
\text { engineering (1); process simulation visualization (1); tacit } \\
\text { knowledge transfer visualization (1); knowledge modeling } \\
\text { description language (1). }\end{array}$} & {$[27],[74]$} & Knowledge transfer & $\begin{array}{l}\text { - How can Human-CPPS } \\
\text { interaction facilitate } \\
\text { knowledge-based } \\
\text { design? } \\
\text { - What benefit can Human-CPPS } \\
\text { interaction provide for a } \\
\text { knowledge-based } \\
\text { design? }\end{array}$ \\
\hline & $\begin{array}{l}\text { Process } \\
\text { Modeling }\end{array}$ & & {$[76],[48]$} & $\begin{array}{l}\text { Knowledge Transfer } \\
\text { Knowledge Creation }\end{array}$ & $\begin{array}{l}\text { - How are process modeling } \\
\text { languages developing new } \\
\text { business processes? } \\
\text { - How having quantitative } \\
\text { approach in using process } \\
\text { modeling languages can rise a } \\
\text { comprehension for its use? }\end{array}$ \\
\hline
\end{tabular}

Table 1 - Summary of the Bibliometric Analysis and Literature Review Findings. 
We began by analyzing the evolution of topics in the different clusters over time (see Figure 2). As described by Ortiz-de-Urbina-Criado, et al. [77], the diverse colors assigned to topics are based on the occurrence frequencies over the past two years. It provides a representation of how emerging topics have been formed over the timespan and individuates those receiving more recent attention.

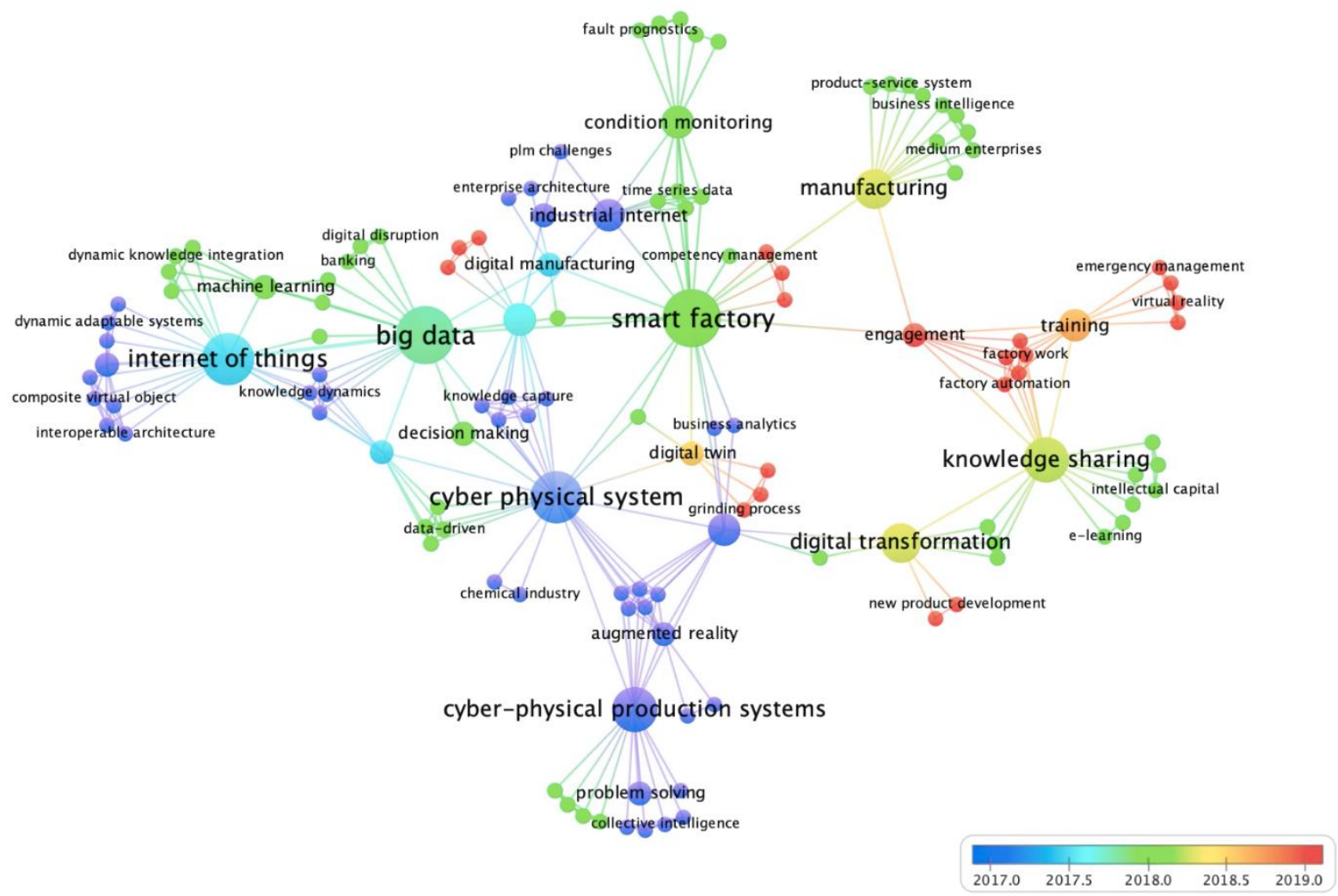

Fig. 2. Evolution of topics over time.

At the beginning of 2017 , the most common topics were 'cyber physical system,' 'industrial internet,' 'process modeling,' and 'cyber-physical production systems.' Later in the same year, 'internet of things' and 'digital manufacturing' gained the highest frequency. In the first few months of 2018, 'big data,' 'smart factory,' and 'condition monitoring' were among those with the highest relative frequency. Topics such as 'digital manufacturing,' 'manufacturing,' and 'knowledge sharing' appeared in the second part of 2018. In 2019, the most frequent topics are 'factory automation,' 'engagement,' 'virtual reality,' and 'new product development.'

In addition to identifying these 'hot' topics, our study investigated the nature of the relationships between KM processes and emerging technologies, resulting from our cluster analysis. As mentioned previously in the quote by Hedlund [4, p.76], KM processes are defined through different activities, namely knowledge acquisition, documentation, transfer, creation, and application. Subsequently, each KM process, according to each specific cluster, forms a unique contribution. Knowledge acquisition combines intangible tacit and tangible explicit knowledge obtain from the external environment by an organization. This process is mostly targeted in the aqua and purple clusters and in relation to technologies, such as digital twin, semantic web, and semantic web rule language, which are focused primarily on knowledge acquisition capability. Knowledge documentation relates to the process of storing and retrieving knowledge form organizational systems (e.g., databases). Accordingly, studies dealing with this process were linked to two sub-streams, including DT and $C P S$, respectively, in the red and green clusters. Our study reveals that this process was mostly associated with knowledge capture approaches used to enable storing and reusing knowledge in a 
digital environment. Knowledge transfer/sharing is the process by which employees are able to share their tacit or explicit knowledge within and outside of the organization. This was the most inquired process (i.e., in 66\% of the papers) and common to all clusters and to many sub-streams (e.g., cps, smart factory, manufacturing, process modeling). This process is addressed effectively in the 'factory of future,' 'Factory2Fit,' 'operator 4.0,' and 'organization 4.0' concepts. Knowledge creation involves ways to facilitate the creation of new knowledge from both tacit and implicit knowledge inside the organization and is a central topic, as approximately half of the papers in the dataset address it. The aqua and purple clusters, especially in the condition monitoring and process modeling substreams, have strong connections with the knowledge transfer process. Additionally, semantic technologies and ontology-based models are frameworks to extend knowledge transferability in smart and digital environments. Knowledge application is the process by which knowledge, either tacit or explicit, is reused within an organization. However, this process is the least investigated, as only $16 \%$ of the papers in the dataset address it. Only the aqua cluster truly considers its implications thoroughly and focuses on innovative client-centered approaches, specifically in the banking industry.

Based on these further elaborations, we attempted to envision future directions regarding KM practices and determine how different practice categories relate to various firm performance outcomes. We used a classification approach described by Inkinen [78, p. 232] in his recent literature review of KM practices to develop a clear interpretation of our findings. He considered KM as related to four main foci: human-related KM practices, primarily the human aspects and consequences of KM (e.g., culture, people, and leadership); organization-related KM practices, mainly the overall organizational system (e.g., organizational processes and structures).; technology-related KM practices (e.g., infrastructure and applications); and management process-related KM practices (e.g., strategies, goals, and measurement).

In relation to human-centered KM practices, the CPPS stream emphasizes how knowledge sharing and reciprocal learning can be enhanced [27, 74]. The same challenge is identified in the establishment of CPPS design with a specific relationship to human interactions [79]. Therefore, there is a need for more knowledge-based support of human planners, providing timely information and knowledge in the right context, where it can be fruitful. According to Francalanza, et al. [79], few studies have considered CPPS and design activities. Consequently, CPPS design should include a more thorough understanding of the digital factory and its consequences for human capital. Hence, CPPS designs that promote human-CPPS interaction can be studied further.

Regarding organizational-related KM practices, CPS, big data, and manufacturing may be a fruitful avenue of further investigation. For example, CPS studies have made a positive contribution to knowledge sharing mechanisms, both vertical and horizontal. Knowledge sharing behaviors can boost learning among staff and improve problem solving ability by sharing past experiences, thus fostering quicker responses to emerging problems [80]. This type of learning can also occur at different levels of the organization (i.e., individual, group, institutional) Crossan, et al. [81]. Therefore, we encourage more studies of outcomes at different organizational levels.

Big data is another valuable topic of organizational-level KM research [82]. Thus far, investments in big data technologies have not provided any direct benefits. For this reason, Ferraris, et al. [83] emphasize the organizational capabilities required to exploit the advantages of big data, namely big data analytics (BDA) and KM capabilities. The impact of big data capabilities as a new competitive advantage in relation to creating new knowledge needs to be further developed.

Manufacturing studies are the third stream that reveals particular contributions to organizationalrelated knowledge management practices, especially knowledge sharing. In the emerging knowledgeintensive environment, there is a need to balance the vital necessity of sharing to gain new insights and the risk of knowledge leakages. Specifically, studies have so far failed to address the problem and identify ways to balance open collaboration and the necessity to create a trustworthy network. For this reason, we suggest focusing more attention on this aspect.

Considering the technology-related KM practices that may be involved in the IoT, focusing on condition monitoring, and process modeling could advance the discussion on utilizing technology for 
efficient knowledge management. First, the IoT is a tool that enables on-demand data access for individuals and organizations. As Chesbrough [84] states, open innovation can refer to the accessibility of knowledge/information both within and outside of the organization, which may stimulate a discussion of ICT technologies and development in emerging open innovation paradigms (e.g., the inbound open innovation model). These considerations need to be rethought and reshaped in relation to business models. Condition monitoring is another stream of research that can contribute to advancing technology-related aspects as they facilitate fault identification by processing information collected via different devices or sensors. As Cristaldi, et al. [85] explains, although condition monitoring assists in monitoring the life-cycle costs of products, the level of uncertainty is high [86]. Specifically, there is a lack of knowledge about inputs and their reliability and accuracy. Thus, our study aims to shed light on the benefits that condition monitoring systems/techniques may offer in the management of existing uncertainty. Process modeling languages have become more important in developing business processes [76]. Indeed, in the volatile Industry 4.0 environment, where business processes are becoming continuously more knowledge-intensive, the need for developing tools to analyze them efficiently is crucial. Finally, regarding management process-related KM practices, two streams of research are relevant, specifically smart factories and DT, suggesting they are strategic to improving $\mathrm{KM}$ implementation (e.g., using $\mathrm{KM}$ tools to accomplish organizational objectives).

In relation to the fist stream, the importance of modeling production processes is confirmed in the context of smart factories. This evolution can have a profound impact on business models in general and may lead to the emergence of completely new combinations of its elements [89]. One of the critical factors for success are knowledge sharing and the creation of a knowledge-sharing culture among employees. For this reason, we identify business models in smart factories as an underexplored topic. The second stream of the DT-related literature reveals how this impacts new product development (NPD). In particular, Schweitzer, et al. [87] discovered that companies with a strong NPD-orientation may thrive during a DT. Indeed, NPD processes that rely on IT-based workflows and product data management practices are most successful when integrated with the overall company's strategy. Thus, our study informs further research on how DT may change a company's strategies Kahn, et al. [88].

\section{CONCLUDING REMARKS}

This study constitutes the first attempt to conduct a detailed, systematic, and objective review of academic research in the KM literature in the Industry 4.0 era. Bibliometric analysis was used in the investigation and helped discover the structure of the field and identify fruitful avenues for further research, in line with our two research questions. After the analysis, a systematic literature review was also performed in relation to the cluster results, identifying the unique contribution of each cluster.

The insights gained from this study have some implications for academics and practitioners. From an academic perspective, the bibliometric analysis carried out lays the groundwork to help determine how KM and its practices are evolving in the digital era, thus providing scholars with a proper systematization of knowledge regarding the research field. From a practical perspective, the findings of this research suggest that practitioners in the KM field should consider, understand, and integrate different dimensions of Industry 4.0 advancements in their organizations, which will help mitigate the potential negative effects on organizational performance.

This study has some limitations. The analysis of keyword co-occurrence provides a small number of significant clusters considering the number of occurrences of keywords. For this reason, the results seem to show significant fragmentation of some terms in some clusters. For future research, it would be of interest to employ other bibliometric techniques (e.g., bibliographic coupling or co-citation analysis), which would complement this study and help to further develop the KM field.

\section{REFERENCES}


[1] C. Bandera, F. Keshtkar, M. R. Bartolacci, S. Neerudu, and K. Passerini, "Knowledge management and the entrepreneur: Insights from Ikujiro Nonaka's Dynamic Knowledge Creation model (SECI)," International Journal of Innovation Studies, vol. 1, no. 3, pp. 163174, 2017.

[2] H. Nam Nguyen and S. Mohamed, "Leadership behaviors, organizational culture and knowledge management practices: An empirical investigation," Journal of Management Development, vol. 30, no. 2, pp. 206-221, 2011.

[3] I. Nonaka and V. Peltokorpi, "Objectivity and subjectivity in knowledge management: a review of 20 top articles," Knowledge and process management, vol. 13, no. 2, pp. 73-82, 2006.

[4] G. Hedlund, "A model of knowledge management and the N-form corporation," Strategic management journal, vol. 15, no. S2, pp. 73-90, 1994.

[5] D. Boyd and K. Crawford, "Critical questions for big data: Provocations for a cultural, technological, and scholarly phenomenon," Information, communication \& society, vol. 15, no. 5, pp. 662-679, 2012.

[6] T. Sarina, "Enhancing knowledge management (KM) in the fourth industrial revolution era: The role of human resource systems," in The Palgrave Handbook of Knowledge Management: Springer International Publishing, 2018, pp. 411-435.

[7] P. K. Muhuri, A. K. Shukla, and A. Abraham, "Industry 4.0: A bibliometric analysis and detailed overview," Engineering Applications of Artificial Intelligence, vol. 78, pp. 218-235, 2019.

[8] E. Oztemel and S. Gursev, "Literature review of Industry 4.0 and related technologies," Journal of Intelligent Manufacturing, pp. 1-56, 2018.

[9] E. Di Maria, M. Bettiol, M. Capestro, and A. Furlan, "Do industry 4.0 technologies lead to more (and better) knowledge?," in 19th European Conference on Knowledge Management, ECKM 2018, 2018, vol. 1, pp. 174-181: Academic Conferences Limited.

[10] W. Zong, F. Wu, and Z. Jiang, "A Markov-based update policy for constantly changing database systems," IEEE Transactions on Engineering Management, vol. 64, no. 3, pp. 287300, 2017.

[11] B. Choi, S. K. Poon, and J. G. Davis, "Effects of knowledge management strategy on organizational performance: A complementarity theory-based approach," Omega, vol. 36, no. 2, pp. 235-251, 2008.

[12] G. Santoro, D. Vrontis, A. Thrassou, and L. Dezi, "The Internet of Things: Building a knowledge management system for open innovation and knowledge management capacity," Technological Forecasting and Social Change, vol. 136, pp. 347-354, 2018.

[13] S. Erickson and H. Rothberg, "Big data and knowledge management: establishing a conceptual foundation," Electronic Journal of Knowledge Management, vol. 12, no. 2, p. 101, 2014.

[14] P. M. Podsakoff, S. B. MacKenzie, N. P. Podsakoff, and D. G. Bachrach, "Scholarly influence in the field of management: A bibliometric analysis of the determinants of university and author impact in the management literature in the past quarter century," Journal of Management, vol. 34, no. 4, pp. 641-720, 2008.

[15] A. Serenko, N. Bontis, L. Booker, K. Sadeddin, and T. Hardie, "A scientometric analysis of knowledge management and intellectual capital academic literature (1994-2008)," Journal of knowledge management, vol. 14, no. 1, pp. 3-23, 2010.

[16] P. Mongeon and A. Paul-Hus, "The journal coverage of Web of Science and Scopus: a comparative analysis," Scientometrics, vol. 106, no. 1, pp. 213-228, 2016.

[17] N. J. van Eck, L. Waltman, J. van den Berg, and U. Kaymak, "Visualizing the computational intelligence field [Application Notes]," IEEE Computational Intelligence Magazine, vol. 1, no. 4, pp. 6-10, 2006. 
[18] D. Tranfield, D. Denyer, and P. Smart, "Towards a methodology for developing evidenceinformed management knowledge by means of systematic review," British journal of management, vol. 14, no. 3, pp. 207-222, 2003.

[19] N. J. van Eck and L. Waltman, "VOSviewer manual," Leiden: Univeristeit Leiden, vol. 1, no. 1, 2013.

[20] N. van Eck and L. Waltman, "Software survey: VOSviewer, a computer program for bibliometric mapping," Scientometrics, vol. 84, no. 2, pp. 523-538, 2009.

[21] Y. Ding, R. Rousseau, and D. Wolfram, Measuring scholarly impact. Springer, 2016.

[22] M. J. Cobo, A. G. López-Herrera, E. Herrera-Viedma, and F. Herrera, "An approach for detecting, quantifying, and visualizing the evolution of a research field: A practical application to the fuzzy sets theory field," Journal of Informetrics, vol. 5, no. 1, pp. 146166, 2011.

[23] N. J. Van Eck and L. Waltman, "Visualizing bibliometric networks," in Measuring scholarly impact: Springer, 2014, pp. 285-320.

[24] K. Sampigethaya and R. Poovendran, "Aviation cyber-physical systems: Foundations for future aircraft and air transport," Proceedings of the IEEE, vol. 101, no. 8, pp. 1834-1855, 2013.

[25] M. M. Waris, C. Sanin, and E. Szczerbicki, "Community of Practice for Product Innovation Towards the Establishment of Industry 4.0," in 10th International scientific conferences on research and applications in the field of intelligent information and database systems, ACIIDS 2018 vol. 10752 LNAI, D. H. Hoang, T. P. Hong, N. T. Nguyen, B. Trawinski, and H. Pham, Eds., ed: Springer Verlag, 2018, pp. 651-660.

[26] E. A. Lee and S. A. Seshia, Introduction to embedded systems: A cyber-physical systems approach. Mit Press, 2016.

[27] F. Ansari, M. Khobreh, U. Seidenberg, and W. Sihn, "A problem-solving ontology for human-centered cyber physical production systems," (in English), CIRP Journal of Manufacturing Science and Technology, Article vol. 22, pp. 91-106, 2018.

[28] S. Song, Y. Lin, B. Guo, Q. Di, and R. Lv, "Scalable distributed semantic network for knowledge management in cyber physical system," Journal of Parallel and Distributed Computing, vol. 118, pp. 22-33, 2018.

[29] A. Sivanathan, J. M. Ritchie, and T. Lim, "A novel design engineering review system with searchable content: knowledge engineering via real-time multimodal recording," (in English), Journal of Engineering Design, Article vol. 28, no. 10-12, pp. 681-708, 2017.

[30] C. Scheuermann, B. Bruegge, J. Folmer, and S. Verclas, "Incident Localization and Assistance System: A case study of a Cyber-Physical Human System," in 2015 IEEE/CIC International Conference on Communications in China - Workshops, CIC/ICCC 2015, 2017, pp. 57-61: Institute of Electrical and Electronics Engineers Inc.

[31] L. Mládková, "Industry 4.0: Human-Technology interaction: Experience learned from the aviation industry," in 19th European Conference on Knowledge Management, ECKM 2018, 2018, vol. 1, pp. 571-578: Academic Conferences Limited.

[32] Q. Cao, C. Zanni-Merk, and C. Reich, "Towards an ontological representation of condition monitoring knowledge in the manufacturing domain," in 10th International Joint Conference on Knowledge Discovery, Knowledge Engineering and Knowledge Management, IC3K 2018, 2018, vol. 2, pp. 312-318: SciTePress.

[33] S. Nandi, H. A. Toliyat, and X. Li, "Condition monitoring and fault diagnosis of electrical motors-A review," IEEE transactions on energy conversion, vol. 20, no. 4, pp. 719-729, 2005.

[34] P. Papadopoulos and L. Cipcigan, "Wind turbines' condition monitoring: an ontology model," in 2009 International Conference on Sustainable Power Generation and Supply, 2009, pp. 1-4: IEEE. 
[35] J. Schwarzenbach, L. Wilkinson, M. West, and M. Pilling, "Mapping the remote condition monitoring architecture," Research Programme. Rail Safety and Standards Boards (RSSB) LTD. RSSB Core Report, 2010.

[36] W. Wu, Y. Zheng, K. Chen, X. Wang, and N. Cao, "A Visual Analytics Approach for Equipment Condition Monitoring in Smart Factories of Process Industry," in 11th IEEE Pacific Visualization Symposium, Pacific Vis 2018, 2018, vol. 2018-April, pp. 140-149: IEEE Computer Society.

[37] Q. Cao, "Semantic technologies for the modeling of condition monitoring knowledge in the framework of industry 4.0," in 2018 EKAW Doctoral Consortium, EKAW-DC 2018, 2018, vol. 2306: CEUR-WS.

[38] D. Laney, "3D data management: Controlling data volume, velocity and variety," META group research note, vol. 6, no. 70, p. 1, 2001.

[39] J. S. Ward and A. Barker, "Undefined by data: a survey of big data definitions," arXiv preprint arXiv:1309.5821, 2013.

[40] P. P. Tallon, "Corporate governance of big data: Perspectives on value, risk, and cost," Computer, vol. 46, no. 6, pp. 32-38, 2013.

[41] R. Blumberg and S. Atre, "The problem with unstructured data," Dm Review, vol. 13, no. 42-49, p. 62, 2003.

[42] K. Mungai and A. Bayat, "The impact of big data on the South African banking industry," in 15th International Conference on Intellectual Capital, Knowledge Management and Organisational Learning, ICICKM 2018, 2018, vol. 2018-November, pp. 225-236: Academic Conferences and Publishing International Limited.

[43] Z. Khan and T. Vorley, "Big data text analytics: an enabler of knowledge management," Journal of Knowledge Management, vol. 21, no. 1, pp. 18-34, 2017.

[44] R. Costa, P. Figueiras, R. Jardim-Goncalves, J. Ramos-Filho, and C. Lima, "Semantic enrichment of product data supported by machine learning techniques," in $23 \mathrm{rd}$ International Conference on Engineering, Technology and Innovation, ICE/ITMC 2017, 2018, pp. 1472-1479: Institute of Electrical and Electronics Engineers Inc.

[45] Q. Bao, J. Wang, and J. Cheng, "Research on ontology modeling of steel manufacturing process based on big data analysis," in 7th International Conference on Mechatronics and Manufacturing, ICMM 2016, 2016, vol. 45: EDP Sciences.

[46] S. Peroni and F. Vitali, "Interfacing fast-fashion design industries with Semantic Web technologies: The case of Imperial Fashion," (in English), Journal of Web Semantics, Article vol. 44, pp. 37-53, 2017.

[47] L. J. A. Cárdenas, W. F. T. Ramírez, and J. I. Rodríguez Molano, "Model for the incorporation of big data in knowledge management oriented to industry 4.0," in $3 \mathrm{rd}$ International Conference on Data Mining and Big Data, DMBD 2018 held in conjunction with the 9th International Conference on Swarm Intelligence, ICSI 2018 vol. 10943 LNCS, Y. Shi, Q. Tang, and Y. Tan, Eds., ed: Springer Verlag, 2018, pp. 683-693.

[48] R. Lee, I. Y. Chen, and P. Nichols, "A novel production process modeling for analytics," (in English), International Journal of GEOMATE, Article vol. 11, no. 2, pp. 2370-2377, 2016.

[49] F. Longo, L. Nicoletti, and A. Padovano, "Ubiquitous knowledge empowers the Smart Factory: The impacts of a Service-oriented Digital Twin on enterprises' performance," (in English), Annual Reviews in Control, Article 2019.

[50] E. J. Tuegel, A. R. Ingraffea, T. G. Eason, and S. M. Spottswood, "Reengineering aircraft structural life prediction using a digital twin," International Journal of Aerospace Engineering, vol. 2011, 2011.

[51] A. Padovano, F. Longo, L. Nicoletti, and G. Mirabelli, "A Digital Twin based Service Oriented Application for a 4.0 Knowledge Navigation in the Smart Factory," (in English), IFAC-PapersOnLine, Article vol. 51, no. 11, pp. 631-636, 2018. 
[52] M. Graczyk-Kucharska, M. Szafranski, M. Golinski, M. Spychala, and K. Borsekova, "Model of competency management in the network of production enterprises in industry 4.0-Assumptions," in 5th International Scientific-Technical Conference on Advances in Manufacturing, MANUFACTURING 2017, A. Hamrol, O. Ciszak, S. Legutko, and M. Jurczyk, Eds., ed: Springer Heidelberg, 2018, pp. 195-204.

[53] M. A. Jarwar, S. Ali, M. G. Kibria, S. Kumar, and I. Chong, "Exploiting interoperable microservices in web objects enabled Internet of Things," in 9th International Conference on Ubiquitous and Future Networks, ICUFN 2017, 2017, pp. 49-54: IEEE Computer Society.

[54] F. Burzlaff, N. Wilken, C. Bartelt, and H. Stuckenschmidt, "Semantic interoperability methods for smart service systems: A survey," IEEE Transactions on Engineering Management, 2019.

[55] M. Thoma, T. Braun, C. Magerkurth, and A.-F. Antonescu, "Managing things and services with semantics: A survey," in 2014 IEEE Network Operations and Management Symposium (NOMS), 2014, pp. 1-5: IEEE.

[56] J. I. Rodríguez-Molano, L. E. Contreras-Bravo, and E. Rivas-Trujillo, "Industry knowledge management model 4.0," in International Conference on Information Technology and Systems, ICITS18 vol. 721, A. Rocha and T. Guarda, Eds., ed: Springer Verlag, 2018, pp. 275-283.

[57] I. Lee and O. Sokolsky, "Medical cyber physical systems," in Design automation conference, 2010, pp. 743-748: IEEE.

[58] D. Djurdjanovic, L. Mears, F. A. Niaki, A. U. Haq, and L. Li, "State of the Art Review on Process, System, and Operations Control in Modern Manufacturing," (in English), Journal of Manufacturing Science and Engineering, Transactions of the ASME, Review vol. 140, no. 6, 2018, Art. no. 061010.

[59] F. Burzlaff and C. Bartelt, "Knowledge-driven architecture composition: Case-based formalization of integration knowledge to enable automated component coupling," in 2017 IEEE International Conference on Software Architecture Workshops, ICSAW 2017, 2017, pp. 108-111: Institute of Electrical and Electronics Engineers Inc.

[60] S. I. Toc and A. Korodi, "Modbus-OPC UA Wrapper Using Node-RED and IoT-2040 with Application in the Water Industry," in 16th IEEE International Symposium on Intelligent Systems and Informatics, SISY 2018, 2018, pp. 99-103: Institute of Electrical and Electronics Engineers Inc.

[61] I. S. Candanedo, E. H. Nieves, S. R. González, M. T. S. Martín, and A. G. Briones, "Machine learning predictive model for industry 4.0," in 13th International Conference on Knowledge Management in Organizations, KMO 2018 vol. 877, B. Hadzima, L. Uden, and I. Ting, Eds., ed: Springer Verlag, 2018, pp. 501-510.

[62] A. Zangiacomi, M. Sacco, E. Pessot, A. De Zan, and M. Bertetti, "A Perspective for the Implementation of a Path Towards the Factory of the Future: The Italian Case," in 2018 IEEE International Conference on Engineering, Technology and Innovation, ICE/ITMC 2018, 2018: Institute of Electrical and Electronics Engineers Inc.

[63] I. E. Commission, "Factory of the future," White Pap. Futur. Fact, pp. 44-47, 2015.

[64] D. Li, D. Paulin, A. Fast-Berglund, P. Gullander, and L. O. Bligård, "Supporting individual needs for intra-organisational knowledge sharing activities in pre-industry 4.0 SMEs," in 15th International Conference on Intellectual Capital, Knowledge Management and Organisational Learning, ICICKM 2018, 2018, vol. 2018-November, pp. 160-170: Academic Conferences and Publishing International Limited.

[65] S. Aromaa et al., "User Evaluation of Industry 4.0 Concepts for Worker Engagement," in 1st International Conference on Human Systems Engineering and Design: Future Trends and Applications, IHSED 2018 vol. 876, T. Ahram, R. Taiar, and W. Karwowski, Eds., ed: Springer Verlag, 2019, pp. 34-40. 
[66] B. Sherehiy and W. Karwowski, "The relationship between work organization and workforce agility in small manufacturing enterprises," International Journal of Industrial Ergonomics, vol. 44, no. 3, pp. 466-473, 2014.

[67] R. M. Grant, "The knowledge-based view of the firm," The strategic management of intellectual capital and organizational knowledge, vol. 17, no. 2, pp. 133-148, 2002.

[68] M. Wolf, A. Semm, and C. Erfurth, "Digital transformation in companies - challenges and success factors," in 18th International Conference on Innovations for Community Services, I4CS 2018 vol. 863, C. Erfurth, G. Fahrnberger, G. Eichler, and M. Hodon, Eds., ed: Springer Verlag, 2018, pp. 178-193.

[69] N. M. Ochara et al., "Digital Transformation of Enterprises: A Transition Using Process Modelling Antecedents," in 2018 Open Innovations Conference, OI 2018, 2018, pp. 325331: Institute of Electrical and Electronics Engineers Inc.

[70] J. Bibaud-Alves, H. B. El-Haouzi, P. Thomas, and V. Boucinha, "Toward a sustainable new product development approach based on industry 4.0 assets," in International Workshop Service Orientation in Holonic and Multi-agent Manufacturing, SOHOMA'18 vol. 803, S. Cavalieri, A. Thomas, D. Trentesaux, and T. Borangiu, Eds., ed: Springer Verlag, 2019, pp. 156-167.

[71] I. Ilvonen, S. Thalmann, M. Manhart, and C. Sillaber, "Reconciling digital transformation and knowledge protection: A research agenda," (in English), Knowledge Management Research and Practice, Article vol. 16, no. 2, pp. 235-244, 2018.

[72] L. Monostori et al., "Cyber-physical systems in manufacturing," Cirp Annals, vol. 65, no. 2, pp. 621-641, 2016.

[73] H. Kagermann, J. Helbig, A. Hellinger, and W. Wahlster, Recommendations for implementing the strategic initiative INDUSTRIE 4.0: Securing the future of German manufacturing industry; final report of the Industrie 4.0 Working Group. Forschungsunion, 2013.

[74] F. Ansari and U. Seidenberg, "A portfolio for optimal collaboration of human and cyber physical production systems in problem-solving," in 13th International Conference on Cognition and Exploratory Learning in Digital Age 2016, CELDA 2016, 2016, pp. 311-314: International Conference on Cognition and Exploratory Learning in Digital Age.

[75] N. Gronau, M. Grum, and B. Bender, "Determining the optimal level of autonomy in cyberphysical production systems," in 2016 IEEE 14th International Conference on Industrial Informatics (INDIN), 2016, pp. 1293-1299: IEEE.

[76] M. Grum and N. Gronau, "Integration of augmented reality technologies in process modeling the augmentation of real world scenarios with the kmdl," in 7th International Symposium on Business Modeling and Software Design, BMSD 2017, 2017, pp. 206-215: SciTePress.

[77] M. Ortiz-de-Urbina-Criado, J.-J. Nájera-Sánchez, and E.-M. Mora-Valentín, "A Research Agenda on Open Innovation and Entrepreneurship: A Co-Word Analysis," Administrative Sciences, vol. 8, no. 3, p. 34, 2018.

[78] H. Inkinen, "Review of empirical research on knowledge management practices and firm performance," Journal of knowledge management, vol. 20, no. 2, pp. 230-257, 2016.

[79] E. Francalanza, J. Borg, and C. Constantinescu, "A knowledge-based tool for designing cyber physical production systems," Computers in Industry, vol. 84, pp. 39-58, 2017.

[80] P. J. Sher and V. C. Lee, "Information technology as a facilitator for enhancing dynamic capabilities through knowledge management," Information \& management, vol. 41, no. 8, pp. 933-945, 2004.

[81] M. M. Crossan, H. W. Lane, and R. E. White, "An organizational learning framework: From intuition to institution," Academy of management review, vol. 24, no. 3, pp. 522-537, 1999.

[82] M. Gupta and J. F. George, "Toward the development of a big data analytics capability," Information \& Management, vol. 53, no. 8, pp. 1049-1064, 2016. 
[83] A. Ferraris, A. Mazzoleni, A. Devalle, and J. Couturier, "Big data analytics capabilities and knowledge management: impact on firm performance," Management Decision, 2018.

[84] H. Chesbrough, "Managing open innovation," Research-Technology Management, vol. 47, no. 1, pp. 23-26, 2004.

[85] L. Cristaldi, G. Leone, R. Ottoboni, S. Subbiah, and S. Turrin, "A comparative study on data-driven prognostic approaches using fleet knowledge," in 2016 IEEE International Instrumentation and Measurement Technology Conference Proceedings, 2016, pp. 1-6: IEEE.

[86] H. H. Dewey, D. R. DeVries, and S. R. Hyde, "Uncertainty Quantification in Prognostic Health Management Systems," in 2019 IEEE Aerospace Conference, 2019, pp. 1-13: IEEE.

[87] F. M. Schweitzer, M. Handrich, and S. Heidenreich, "Digital transformation in the new product development process: the role of IT-enabled PLM system for relational, structural, and NPD performance," International Journal of Innovation Management, p. 1950067, 2019.

[88] K. B. Kahn, G. Barczak, J. Nicholas, A. Ledwith, and H. Perks, "An examination of new product development best practice," Journal of product innovation management, vol. 29, no. 2, pp. 180-192, 2012. 